\title{
Efficacy of a preventive instructional module on mothers' knowledge regarding shaken baby syndrome
}

\author{
Sahar Farouk Hashem*1, Boshra Attia Mohammed ${ }^{1}$, Gehan El Nabawy Ahmed ${ }^{1}$, Eman A. Fadel ${ }^{2}$ \\ ${ }^{1}$ Pediatric Nursing Department, Faculty of Nursing, Mansoura University, Egypt \\ ${ }^{2}$ Woman's Health and Midwifery Nursing Department, Faculty of Nursing, Mansoura University, Egypt
}

Received: August 17, 2020

Accepted: October 11, 2020

Online Published: October 19, 2020

DOI: $10.5430 /$ cns.v8n4p35

URL: https://doi.org/10.5430/cns.v8n4p35

\begin{abstract}
Objective: Shaken baby syndrome (SBS) is a shocking phenomenon that is recognized as one of the most severe forms of child abuse with very high rates of morbidity and mortality among infant less than one year of age. Although of its high mortality and morbidity, it is a highly preventable health problem. So, there is an essential need for a strategy to prevent it through education by nurses and physicians to new mothers. This study aimed to evaluate the efficacy of a preventive instructional module on mothers' knowledge regarding SBS.

Methods: A quasi-experimental design was carried out on eighty mothers who had delivered full-term infants and hospitalized on labour and delivery unit affiliated to Mansoura University Hospital, Mansoura City, Egypt. Data were collected through using of a structured interview questionnaire sheet (pre and post-test format) for assessing mothers' knowledge about SBS and infant's crying.

Results: The total mean knowledge scores improved post implementation of a preventive instructional module regarding SBS compared to pre-implementation ( $0.86 \pm 0.19$ versus $0.35 \pm 0.39$ respectively $)$.

Conclusions: The study hypothesis was accepted. There were highly significant improvement in the studied women's knowledge regarding SBS and infant crying. Indicating that the developed preventive instructional module was an effective tool for the enrichment of mothers' knowledge regarding SBS and infant's crying.

Recommendation: Implementation of antenatal classes for improving mothers' knowledge regarding SBS and infant crying.
\end{abstract}

Key Words: Preventive instructional module, Mothers' knowledge, Shaken baby syndrome, Infant's crying

\section{INTRODUCTION}

Shaking a baby is a moment of frustration that changes the parents' life and the life of the baby forever. Shaken Baby Syndrome (SBS) is a type of abusive child head trauma (AHT) ${ }^{[1]}$ It results from violently shaking of an infant shoulders, arms, or legs by caregivers resulting in bleeding within the brain or the eyes. ${ }^{[2]}$ The commonest age for SBS is the age of six months and it can affect children until the age of two years. SBS has long-term disabilities which can be caused by the effect of SBS such as learning disabilities, growth and developmental delay, behavioral disorders and cortical blindness. Beside to, lifelong brain injury, subdural and retinal hemorrhage, spinal cord damage and rib and neck fracture ${ }^{[3]}$ More than $80 \%$ of infants with SBS have lifelong brain injuries. Other risk injuries of shaken baby syndrome are subdural hemorrhages, retinal hemorrhages, damage to the spinal cord and neck, and fractures of the ribs and bones.

\footnotetext{
*Correspondence: Sahar Farouk Hashem; Email: drsaharhashem2013@yahoo.com; Address: Pediatric Nursing Department, Faculty of Nursing, Mansoura University, Egypt.
} 
They often require long-term multidisciplinary medical care and special education. ${ }^{[4]}$

The greatest risk from SBS injury affects infants from 2 to 4 months of age due to the softening of the brain and the thinning of the skull than the older age infants. ${ }^{[5]}$ In addition, due to the weak muscle tone, which is affected when the infant heavy head shaking and whips back and front leading to the bounce off the brain off the skull. The effect of SBS may be delayed as the shaken occur in small seconds but the effect may not appear to the care givers immediately. ${ }^{[6]}$ The babies signs and symptoms may be displayed as vomiting, poor sucking, significant change in the sleep pattern, irritability and uncontrolled crying, bulging fontanels, lethargy and respiratory difficulties or even unresponsiveness and inability to be awakened and coma or death in severe cases. ${ }^{[7]}$

Many factors aggravated the risk for SBS such as younger age parent, parent lower level of education, single parenthood, multiple births, previous history of child maltreatment and low socio-economic status with un-stable social support. ${ }^{[8]}$ Also postpartum maternal tiredness, child care- giver substance abuse, having a premature child or a child with special needs are among the aggravated factors for SBS. ${ }^{[9]}$ Moreover, parents with family risk factors as domestic violence, social isolation, family disorganization, poor negative relation with the child are at risk for committing child abuse. High community poverty rates, high unemployment rates, residential instability, and poor social connections can in crease the likelihood of a parent or caregiver abusing a child under their care. ${ }^{[10]}$

Infant crying is a normal developmental behavior and is an infant's only way to communicate his needs. Episodes of crying typically increase in the first month after birth, peak in the second month, and decrease thereafter. Most infants who cry a lot in early infant are healthy and stop crying spontaneously. ${ }^{[11]}$ Inconsolable or excessive crying is the most trigger for shaking a baby. ${ }^{[12]}$ Up to $38 \%$ of parents identify a problem with their infant crying within the first year. ${ }^{[13]}$ Infant crying is associated with gastro-intestinal disorders, central nervous system abnormalities, and frequent changes of formula, cow's milk protein intolerance, otitis media, urinary tract infection and early weaning from breast milk. ${ }^{[14]}$ Infant's crying that persists over 4 months of age is stressful for most parents, but parental vulnerabilities increase both its impact on parents and the likelihood of the adverse outcomes such as parental depression, infant maltreatment, and longterm problems with child development. ${ }^{[15]}$

Nurses have a vital role in educating the parent how to deal with infant crying instead of abusing by shaken. ${ }^{[16]}$ First of all, nurses should illustrate to the parent how to explore the crying cause to deal with the cause as it may be due to hungry, being thirst or any irritating substance. After fulfilling the infant basic needs, many nursing strategies can be utilized for proper treating of infant crying such as calming by back rubbing, gentle rocking, giving a warm bath, singing or even talking, changing the infant position. ${ }^{[17]}$ Also, other strategies which can calm the infant during crying are placing the baby in safe place or crib for ten or fifteen minutes or can call a relative or a friend to seek assurance. Also, mothers should be educated and trained to check for signs of illness or discomfort like diaper rash, teething, or tight clothing. ${ }^{[18,19]}$

Advanced practice nurses need to have a thorough understanding of abusive head trauma in order to promptly and accurately assess and manage these infants. ${ }^{[20]}$ Early recognition and accurate diagnosis of infant with traumatic head injury are essential for appropriate treatment. Furthermore, if a shaking injury occurs, seeking immediate medical advice is recommended for survival. ${ }^{[21]}$ Most children with SBS will require special services for the lasting period of their lives. These services may include health and mental health care, speech and language, infant stimulation, rehabilitation and special education. Additional supports such as residential placement, adapted housing and employment advocacy may also be needed. ${ }^{[22]}$

So, prevention is better than cure. ${ }^{[23]}$ Nurses should easily provide health education about SBS to all parents during systematic newborn examination given in the prenatal period or at the immediate postpartum period. ${ }^{[24]}$ Nurses have an important role to provide parental information about the normal and abnormal causes of infant crying, the calming strategies to manage the crying, SBS dangers, risk factors and its long-term consequences. ${ }^{[25]}$

\subsection{Significance}

In developing countries, SBSis a chronic neglected infant health issue either from the health care providers or the child-care givers. Although, the well-recognized short and long-term disabilities and complications that may be lifethreatening. There are no accurate statistics. Experts believe that the incidence of SBS varies from 1,000 to 1,500 yearly for infants in their first year of life. SBSis one of the most severe forms of child maltreatment and child abuse, with very high rates morbidity of fifty percent or more and of one- third mortality. ${ }^{[26]}$ SBSis difficult to diagnose. Lack of a centralized reporting system make the incidence is uncertain. In addition, signs of abuse not being present and unclear presented that ends in severe morbidity and mortality. ${ }^{[27]}$ So, assessment of the mothers' knowledge regarding SBS and evaluating the efficacy of a preventive instructional module on their knowledge regarding SBS is very important 
in Egypt as a developing country. Since, most studies on SBS prevention programs were conducted in the developed countries.

\subsection{Aim of the study}

This study aimed to evaluate the efficacy of a preventive instructional module on mothers' knowledge regarding SBS. This aim was accomplished through:

- Assess mothers' knowledge regarding infant's crying and SBS.

- Develop a preventive instructional module for mothers regarding infant's crying and SBS.

- Implement a preventive instructional module for mothers regarding prevention of SBS.

- Evaluate the efficacy of a preventive instructional module on mothers' knowledge regarding prevention of shaken baby syndrome.

- Hypothesis testing

\subsection{Research hypothesis}

Mothers' knowledge regarding prevention of SBSexpected to be improved after implementation of the preventive instructional module.

\section{SubJects ANd Methods}

\subsection{Research design}

A quasi-experimental research design for one group (pre and post-test) was utilized in this study.

\subsection{Setting}

This study was conducted at Labour and Delivery unit postpartum rooms affiliated to Mansoura University Hospital.

\subsection{Sampling}

A convenience sample of (80) mothers of full-term $(\geq$ 37 weeks) and healthy new-borns from the above mentioned setting and they are willing to participate in the study.

\subsection{Sample size}

Based on data from literature, ${ }^{[28]}$ considering level of significance of $5 \%$, and power of study of $80 \%$, the sample size can be calculated using the following Equation 1:

$$
n=\frac{\left[\left(Z_{\frac{\alpha}{2}}+Z_{\beta}\right)^{2} \times 2(S D)^{2}\right]}{{\text { (meandifferencebetweenthetwogroups })^{2}}^{2}}
$$

where, $S D=$ standard deviation

$Z_{\frac{\alpha}{2}}$ : This depends on level of significance, for $5 \%$ this is $1.96 Z_{\beta}$ : This depends on power, for $80 \%$ this is 0.84

Published by Sciedu Press
Therefore, $\left.\left.n=\left[(1.96+0.84)^{2} \times 2(1.7)\right)^{2}\right] /(0.75)\right)^{2}=79.5$

Based on the above formula, the sample size required is 80 .

\subsection{Tool of data collection}

One tool was used to collect the study data, a structured interview questionnaire (pre and post-test format). It was developed by the researchers after reviewing the related literatures and research studies. It included the following three parts:

Part I: General characteristics of the studied sample which divided into:

(1) General characteristics of the studied mothers: It included mothers' age, residence, occupation, level of education, number of children, monthly income, marital status, , presence of the husband in the family and the person who help the mother in caring of child.

(2) General characteristics of the studied infants: It included infant's sex, birth order, method of delivery, causes of infant's crying and the person who calm the infant's during crying.

Part II: Mothers' knowledge about SBS(SBS): It included SBS meaning, causes, purpose of shaking the infant, causes of brain and body injuries resulting from infant shaking, the most common trigger for shaking the baby, high risk factors and high risk group exposed to injuries of SBS, ways which lead to shaking the baby, risk consequences or complications and preventive measures of SBS.

Part III: Mothers' knowledge about infant's crying: It included infant's crying meaning, purposes, time and causes, methods of soothing the infant with severe crying, sources of mothers' knowledge about SBS and infant's crying.

\subsection{Scoring system}

The scoring system of the questions in part II and III of the structured questionnaire was developed as the following: complete correct answer was given the score (2), incomplete correct answer was scored (1) and the wrong or unknown answer was given the score (zero). Mothers' knowledge level was categorized as: satisfactory level of knowledge if the percent score was $\geq 60 \%$, and unsatisfactory level of knowledge if the percent score was $<60 \%$.

\subsection{Validity and reliability}

The structured questionnaire was developed in the English language then translated to the Arabic language .It was translated again to the English language to test its validity by the researchers after reviewing the related literatures. The instructional module which includes an educational video and 
handout about SBS and infant crying was reviewed by professionals in paediatric and maternity nursing before using it with the studied mothers in the study. The hand- out about SBS and infant crying was prepared in a simple Arabic language and include coloured pictures. The tool was tested for its content validity by a group of five experts in the field of paediatric nursing and maternity nursing. The reliability of the tools was tested by using Cronbach's Alpha test that measures the internal consistency of the tools. The reliability of part II regarding mothers' knowledge about SBS(SBS) was 0.849 and Part III about mothers' knowledge about infant's crying was 0.901 , which indicates high reliability.

\subsection{Ethical considerations}

An official permission was obtained by the researchers through letters directed from the Dean of Faculty of Nursing, Mansoura University to the manager of Mansoura University Hospital and the head of Labour and delivery unit to conduct this study after explaining the aim of the study. An informed oral consent was obtained from each mother for her participation. The studied mothers were able to withdraw at any time from the study without any responsibilities.

\subsection{Research process}

\subsubsection{Preparatory Phase}

The researchers reviewed the literatures covering all aspects of shaken baby syndrome, the role of the mothers in managing infant's crying, prevention of SBSand its long term consequences in young age children by using the available text books, articles, journals and internet search to be acquainted with previous and current literature and to develop the relevant tool for data collection and prepare the preventive instructional module.

\section{A pilot study}

A pilot study was carried out to evaluate the applicability, clarity and feasibility of the tool. It was carried out on $10 \%$ (eight mothers) of the total sample size of the studied mothers, and there is no modification. The studied mothers in the pilot study were excluded from the final study sample.

\subsubsection{Baseline assessment}

The researchers communicated with head nurse to explain the study aim and nature. The head nurse introduced the researchers to the mothers, and they invited mothers for voluntary participate in the current study. The aim of the study was explained by the researchers to each studied mother. The data were collected during the period from the start of November 2019 to the end of February 2020. All participants were asked to complete the pre-test questionnaire four hours after delivery for 15 minutes before discharge from the hospital and before implementing of the instructional module.

\subsubsection{Implementation phase}

The instructional handout about SBS was distributed for each participant mother before discharge. (the researchers met the mother after four hours from vaginal delivery or when the mother was able to communicate with the researchers, while communicated with the mother in 2nd. Day from caesarean section). Different teaching methods were used during applying the instructional module as group discussion and role playing. The instructional module included an educational video and handout. Through this module, the studied mothers are provided all information about SBSand infant crying through two sessions. The time of the preventive educational module was 20 minutes for each session. Each participant was contacted via telephone for follow-up by the researchers three months after the implementation of the preventive instructional module.

\subsubsection{Evaluation phase}

The efficacy of the instructional module on mothers' knowledge regarding SBSwas evaluated three months after the implementation of the preventive instructional module.

\subsection{Statistical analysis}

All statistical analyses were performed using SPSS for windows version 20.0 (SPSS, Chicago, IL). All continuous data were normally distributed and were expressed in mean \pm standard deviation $(S D)$. Categorical data were expressed in number and percentage. The comparisons were determined using Student's $t$ test for two variables with continuous data. Chi-square test was used for comparison of variables with categorical data. Statistical significance was set at $p<.05$.

\section{RESULTS}

Table 1 reveals that, More than two-fifths (43.8\%) of the studied mothers aged from twenty- five to thirty years old with a mean $29.5 \pm 4.0$ years old. In relation to mothers' residence, more than two-thirds $(65 \%)$ of them were coming from urban area. Three-quarters $(76.3 \% \& 78.8 \%$ respectively) of them were housewives and had enough family income. Regarding mothers' educational level, slightly more than one-third of them $(33.8 \%)$ were preparatory/secondary graduates. Majority of them $(87.5 \%)$ were married and more than half $(51.3 \%)$ of them had two children.

Table 2 indicates that, more than half $(62.5 \%)$ of infants were girls, slightly more than two-fifths $(41.3 \%)$ of them were the second infant in their family and less than three-quarters of them $(73.8 \%)$ were delivered by caesarean section. 
Table 1. General characteristics of the studied mothers $(\mathrm{n}=80)$

\begin{tabular}{|c|c|c|}
\hline Mother characteristics & No. & $\%$ \\
\hline \multicolumn{3}{|l|}{ Age (years) } \\
\hline$<25$ & 5 & 18.8 \\
\hline $25-30$ & 35 & 43.8 \\
\hline $31-35$ & 22 & 27.5 \\
\hline$>35$ & 8 & 10.0 \\
\hline Mean $\pm S D$ & \multicolumn{2}{|c|}{$29.5 \pm 4.0$} \\
\hline \multicolumn{3}{|l|}{ Residence } \\
\hline Rural & 28 & 35.0 \\
\hline Urban & 52 & 65.0 \\
\hline \multicolumn{3}{|l|}{ Employment } \\
\hline Not working & 61 & 76.3 \\
\hline Working & 19 & 23.8 \\
\hline \multicolumn{3}{|l|}{ Educational level } \\
\hline Illiterate & 8 & 10.0 \\
\hline Read/write & 24 & 30.0 \\
\hline Preparatory/secondary & 27 & 33.8 \\
\hline Higher & 21 & 26.3 \\
\hline \multicolumn{3}{|l|}{ Number of children } \\
\hline One & 15 & 18.8 \\
\hline Two & 41 & 51.3 \\
\hline Three or more & 24 & 30.0 \\
\hline \multicolumn{3}{|l|}{ Income } \\
\hline Not enough & 17 & 21.3 \\
\hline Enough & 63 & 78.8 \\
\hline \multicolumn{3}{|l|}{ Marital status } \\
\hline Married & 70 & 87.5 \\
\hline Divorced & 10 & 12.5 \\
\hline
\end{tabular}

Table 2. General characteristics of the studied infants $(\mathrm{n}=80)$

\begin{tabular}{lcc}
\hline Items & No. & \% \\
\hline Sex & & \\
$\quad$ Girl & 50 & 62.5 \\
$\quad$ Boy & 30 & 37.5 \\
Child's birth order & & \\
$\quad$ First & 17 & 21.3 \\
$\quad$ Second & 33 & 41.3 \\
$\quad$ Third & 25 & 31.3 \\
$\quad$ Fourth & 5 & 6.3 \\
Mode of child's delivery & & \\
$\quad$ Vaginal delivery & 21 & 26.3 \\
$\quad$ Caesarean section & 59 & 73.8 \\
\hline
\end{tabular}

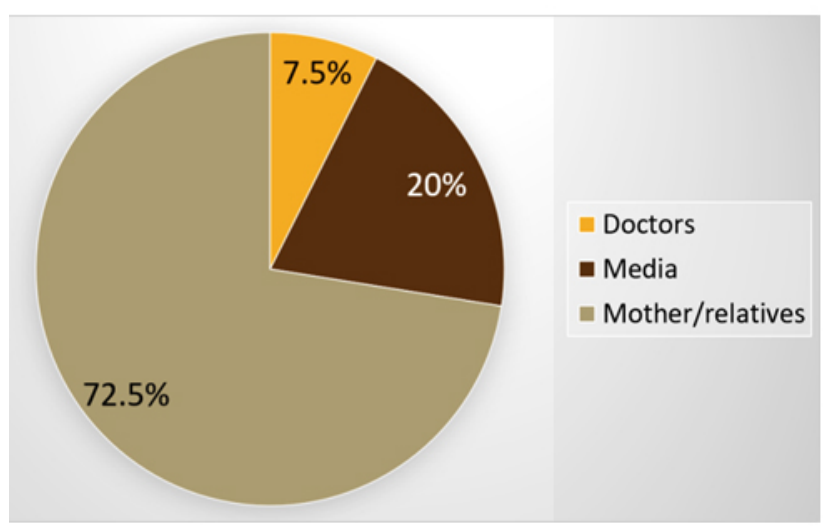

Figure 1. Sources of mothers' knowledge about SBS and infant's crying

Table 3. Comparison of the studied mothers' correct knowledge regarding SBS pre and post-implementation of a preventive instructional module $(\mathrm{n}=80)$

\begin{tabular}{|c|c|c|c|c|}
\hline \multirow{2}{*}{ Items } & Pre & Post & \multirow{2}{*}{$t$-test } & \multirow{2}{*}{$p$} \\
\hline & Mean $\pm S D$ & Mean $\pm S D$ & & \\
\hline Definition of SBS & $0.26 \pm 0.43$ & $0.92 \pm 0.27$ & 8.053 & $<.001^{* *}$ \\
\hline Causes of SBS & $0.37 \pm 0.35$ & $0.97 \pm 0.17$ & 14.407 & $<.001^{* *}$ \\
\hline Purpose of shaking process of the infant & $0.61 \pm 0.5$ & $0.95 \pm 0.21$ & 8.073 & $<.001^{* *}$ \\
\hline The most common trigger for shaking the baby & $0.32 \pm 0.42$ & $0.92 \pm 0.27$ & 12.872 & $<.001^{* *}$ \\
\hline Causes of brain and body injuries resulting from infant shaking & $0.36 \pm 0.47$ & $0.92 \pm 0.27$ & 8.870 & $<.001^{* *}$ \\
\hline Predisposing factors of SBS & $0.33 \pm 0.43$ & $0.95 \pm 0.22$ & 12.162 & $<.001^{* *}$ \\
\hline High risk group exposed to injuries of SBS & $0.36 \pm 0.47$ & $0.95 \pm 0.19$ & 11.459 & $<.001^{* *}$ \\
\hline Ways which lead to shaking the baby & $0.46 \pm 0.43$ & $0.97 \pm 0.14$ & 10.289 & $<.001^{* *}$ \\
\hline Risk consequences or complications of SBS & $0.35 \pm 0.42$ & $0.95 \pm 0.19$ & 14.063 & $<.001^{* *}$ \\
\hline Signs and symptoms of SBS & $0.49 \pm 0.45$ & $0.97 \pm 0.12$ & 9.509 & $<.001^{* *}$ \\
\hline Methods of preventive measures of SBS & $0.37 \pm 0.44$ & $0.96 \pm 0.14$ & 11.591 & $<.001^{* *}$ \\
\hline Total knowledge score & $0.35 \pm 0.39$ & $0.86 \pm 0.19$ & 11.032 & $<.001^{* *}$ \\
\hline
\end{tabular}

Note. ${ }^{* *} p<.001$ Highly statistical significant differences 
Figure 1 clarifies that, less than three-quarters $(72.5 \%)$ of the studied mothers reported that, the relatives were the source of their information about SBS and infant's crying. While, only (7.5\%) of them reported that, health-care providers as doctors and nurses were the source of their information and the rest $(20 \%)$ of them depended on the media for their information about SBS and infant's crying.
Table 3 shows that, there were highly statistically significant differences of the mothers' knowledge regarding SBSpre and post-implementation of the preventive instructional module in all items of knowledge $p<.001$. As evidence by, the total knowledge mean score for SBSimproved from $(0.35 \pm 0.39)$ pre-implementation to $(0.86 \pm 0.19)$ post-implementation of the preventive instructional module regarding SBS.

Table 4. Comparison of the studied mothers' correct knowledge regarding infant's crying Pre and post-implementation of a preventive instructional module $(\mathrm{n}=80)$

\begin{tabular}{|c|c|c|c|c|}
\hline \multirow{2}{*}{ Items } & Pre & Post & \multirow{2}{*}{$t$-test } & \multirow{2}{*}{$p$} \\
\hline & Mean $\pm S D$ & Mean $\pm S D$ & & \\
\hline Meaning of infant's crying & $0.55 \pm 0.46$ & $1.00 \pm 0.37$ & 8.467 & $<.001^{* *}$ \\
\hline Crying is the infant language to grasp mother's attention to his basic needs & $0.41 \pm 0.28$ & $1.00 \pm 0.00$ & 14.379 & $<.001^{* *}$ \\
\hline The time of infant's crying & $0.58 \pm 0.48$ & $1.00 \pm 0.00$ & 7.696 & $<.001^{* * *}$ \\
\hline Causes of infant's crying & $0.66 \pm 0.36$ & $1.00 \pm 0.00$ & 6.496 & $<.001^{* * *}$ \\
\hline Methods of soothing the infant with severe crying & $0.72 \pm 0.38$ & $0.99 \pm 0.02$ & 7.412 & $<.001^{* * *}$ \\
\hline Total knowledge score & $0.58 \pm 0.39$ & $1.00 \pm 0.07$ & 8.891 & $<.001^{* * *}$ \\
\hline
\end{tabular}

Note. ${ }^{* *} p<.001$ Highly statistical significant differences

Table 5. Mothers' knowledge about strategies of soothing the infant's crying pre and post-implementation of a preventive instructional module $(\mathrm{n}=80)$

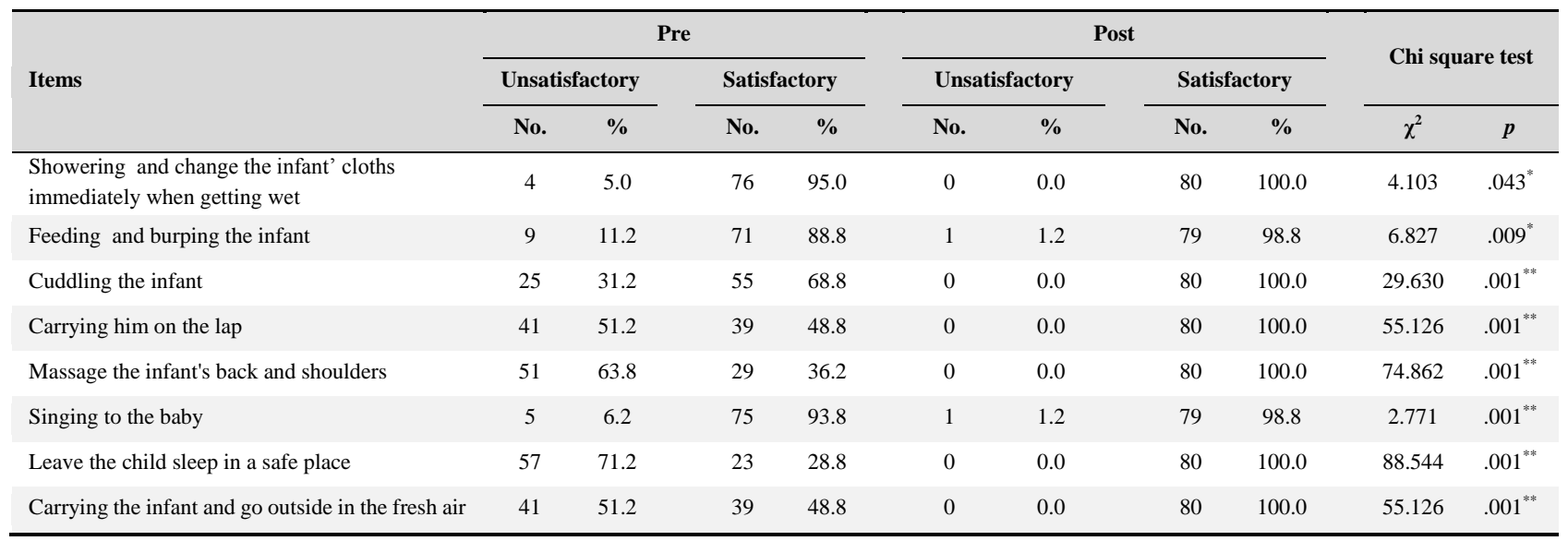

Note. ${ }^{*} p<.05$ Statistical significant differences; ${ }^{* *} p<.001$ Highly statistical significant differences

Table 4 notifies that, there were highly statistically significant differences of the mothers' knowledge regarding infant crying pre and post-implementation of the preventive instructional module in all items of knowledge $p<.001$. As evidence by, the total knowledge mean score for infant crying improved from $(0.58 \pm 0.39)$ Pre-implementation to $(1.00$ \pm 0.07 ) post-implementation of the preventive instructional module regarding SBS.

Table 5 illustrates that there were statistical significant differences between mother's knowledge about all strategies of soothing the infant's crying pre and post-implementation of a preventive instructional module regarding SBS. All
$(100 \%)$ studied mothers had satisfactory level of knowledge compared to only ( $28.8 \% \& 36.2 \%$ respectively) preimplementation regarding leave the child sleep in a safe place and massage the infant's back and shoulders as strategies of soothing the infant's crying.

Table 6 indicates that all $(100 \%)$ of the studied mothers had satisfactory knowledge regarding gaining parental sufficient knowledge about the normal infant pattern of sleep and crying and reducing the environmental stimulus, especially in the first months of infant' life improved postimplementation of the preventive instruction module compared to (21.2\% \& $28.8 \%$ respectively) pre-implementation 
with highly statistical significant differences. Also, there were statistical significant improvement for $(100 \%$ \& $92.5 \%$ respectively) of the studied mothers satisfactory knowledge post-implementation compared to $(88.8 \% \& 75.0 \%$ respectively) pre-implementation regarding using of social media in educating the mothers and fathers about SBS and its risks and the importance of never shaking the infant for any reason. Furthermore, mothers' knowledge about all items of preventive measures of SBS improved with highly statistical significant differences post-implementation of the preventive instruction module than pre-implementation.

Table 6. Mothers' knowledge about the preventive measures of SBS pre and post-implementation of an instructional preventive module $(\mathrm{n}=80)$

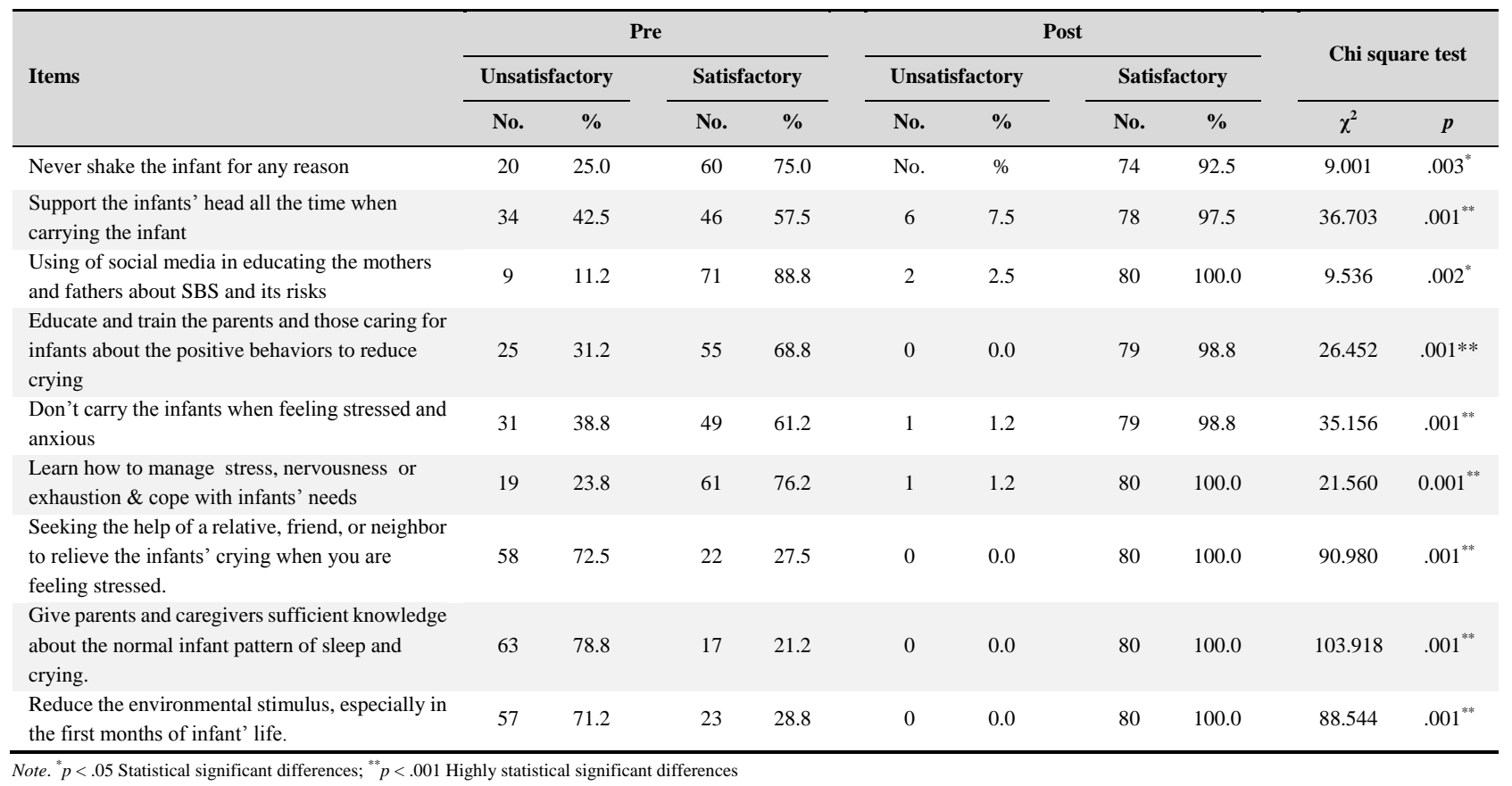

\section{Discussion}

SBS, also known as Abusive Head Trauma (AHT), it is a deadly brain injury condition which is caused by a person who usually is a distressed parent or caregiver violently shaking an infant. ${ }^{[29]}$ Crying conveys evidence about an infant's state and neurological health. When crying is inconsolable or excessive, it can lead to parent stress, and badly place the infant at risk for SBS. ${ }^{[30]}$ In addition to, ${ }^{[33]}$ Wiley illustrated that, infant crying can lead to parental frustration and is the most common trigger for AHT. Abusive Head Trauma is a form of physical abuse and a serious threat to infant health, causing deaths in one-quarter of cases and high morbidity in most survivors. Despite its severity, SBS can be prevented through parent education. ${ }^{[5]}$ The present study aimed to evaluate the efficacy of a preventive instructional module on mothers' knowledge regarding shaken baby syndrome.

The results of the present study revealed that the age of near half of the mothers was ranged between 25-30 years with a mean $29.5 \pm 4.0$ years old. In relation to mothers' residence, more than two third of mothers were coming from urban area, mostly of them were housewives and more than half of them had two children. Educational level as follows; one-third of them was preparatory/secondary school graduates and twenty six percent was university graduates. In addition, the majority was married and had enough monthly family income (see Table 1). These results are not matched with those obtained by Fujiwara, ${ }^{[34]}$ who conducted a study to evaluate the effectiveness of the training materials of a SBS prevention programme for parents in Turkey, and found that, the mean age of the mothers was $27.6 \pm 5.5$ years; educational levels were as follows: 51.2 percent had primary school graduates, 28.3 percent had high school graduates and $20.5 \%$ had university graduates.

As regards infants' characteristics, the finding of our study indicated that more than two-thirds of infants were girls. More than two-fifths of them were the second infant in their family and most of them were delivered by caesarean section (see Table 2). These study findings were in harmony with Mohebatia, ${ }^{[35]}$ who conducted a study to describe reported infant crying patterns in a cohort study of Mexican infants. They found that, forty-seven percent of infants were male 
and less than half were delivered vaginally.

Concerning sources of mothers' knowledge about SBS and infant's crying, the present study findings shown that mostly of mothers reported that the relatives were the main source of their knowledge about SBS and infant's crying. While the minority of them reported that the health care providers were their source of information (see Figure 1). This may be related to our cultural issue regarding close communication with the relatives and family members. These study findings were not matched with those obtained by Lopez-Bushnell ${ }^{[36]}$ who conducted a study to educate parents of hospitalized infants on the prevention of SBS, and found that, seventy-eight percent of parents remembered a nurse, social worker, or other health educator speaking to them about SBS, receiving written materials about SBS, and what to do when their baby cries. Ninety-nine percent remembered watching a video about SBS. 83\% received information on SBS while they were in the hospital or after the baby was delivered. Sixtyfive percent of parents reported that they shared the SBS information with others who care for their child.

The findings of the present study illustrated that, the studied mothers' knowledge regarding SBS and infant crying had improved after implementation of the preventive instructional module than before (see Tables $3 \& 4$ ). These present study findings may be attributed to the mean of the mothers age was $29.5 \pm 4.0$ years old, and majority of them had secondry and university education which facilitate gaining the instruction provided. Also, this study finding may be attributed to the simplicity and attractiveness of the developed preventive instructional module which made in a simple Arabic language and the utilizing of coloured pictures and simple illustrated videos. Furthermore, the novelty of this infant health- issue of SBS for the studied mother and the mothers' interest to gain such new information may attribute to such study findings.

These study findings corroborated with a cross sectional design conducted by Fujiwara, ${ }^{[31]}$ on 1316 women to investigate the impact of public health practices to prevent SBS/AHT in Japan. The researcher concluded that there were higher statistical improvement in the caregiver information regarding infant crying and SBS. Also, the findings of Ornstein ${ }^{[32]}$ who studied parents' perceptions of infant crying and indicated that, an increase in parents' knowledge about SBS after implementation of a brief intervention to increase knowledge on SBS. Another experimental study conducted by Wiley ${ }^{[33]}$ on 93 postpartum women in Nova Scotia to determine the effect of postpartum delivery of the educational program on mothers' knowledge about SBS and normal infant crying. Their findings were partially in agreement with the present study findings as they noted a significant statistical improvement in the studied women's knowledge regarding infant crying while, there was an insignificant decrease in the studied women's shaking knowledge. These partial in agreement may be contributed to the participants' high baseline knowledge regarding SBS as it is a well-recognized health issue in the developed country. Providing mothers with adequate knowledge about strategies of soothing the infant's crying can help in prevention of SBS. After implementation of a preventive instructional module, the studied mothers' knowledge regarding the soothing strategies improved significantly than pre-implementation (see Table 5). In accordance, a randomized control trial in Japan and North American conducted by Fujiwara, ${ }^{[31]}$ who concluded that, the utilizing of an educational material to inform the caregivers about infant crying was effective in improving the infant caregiver knowledge regarding crying and prevention of SBS.

The present study indicated that majority of the studied women learned more preventive strategies of SBS postimplementation of the preventive instructional module with statistical significant differences than before (see Table 6). These study findings were in the same line with the finding of a randomized controlled trial conducted by Fujiwara, ${ }^{[34]}$ they found improvement in the participants' awareness about the normal infant pattern crying and the preventive measure of SBS after the intervention of providing information regarding SBS and infant crying.

\section{Conclusions}

Based on the study findings, the study hypothesis was accepted. There were highly significant improvement in the studied women's knowledge regarding SBS and infant crying. Indicating that the preventive instructional module was an effective tool for the enrichment of mothers' knowledge regarding SBS and infant's crying.

\section{Recommendations}

- Implementation of antenatal classes for improving mothers' knowledge regarding SBS and infant crying.

- Assess the association of parents positive behavior related to infant's crying and the incidence of shaken baby syndrome (SBS).

- Utilizing hospital-based education for new parents to improve their knowledge about SBS.

- The inclusion of fathers and male caregivers in future studies should be considered for completing the educational program evaluation. 


\section{Limitations of the study}

These Limitations included loss to follow-up, and the lack of database documenting primary prevention efforts and the incidence of SBS. Many follow-up phone calls were incomplete due to phones being disconnected or parents not an- swering after three attempted phone calls. In addition, we did not have a comparison group that did not undergo the intervention.

\section{Conflicts of InTEREST Disclosure}

The authors declare they have no conflicts of interest.

\section{REFERENCES}

[1] Joyce T, Huecker MR. Paediatric Abusive Head Trauma (Shaken Baby Syndrome) [Updated 2020 Jun 26]. In: StatPearls [Internet]. Treasure Island (FL): StatPearls Publishing; 2020. Available from: https://www.ncbi.nlm.nih.gov/books/NBK499836/

[2] Elinder G, Eriksson A, Hallberg B, et al. Traumatic shaking: The role of the triad in medical investigations of suspected traumatic shaking. Acta paediatrica. 2018; 107(Suppl 472): 3-23. PMid: 30146789. https://doi.org/10.1111/apa.14473

[3] Barr RG, Barr M, Rajabali F, et al. Eight-year outcome of implementation of abusive head trauma prevention. Child Abuse \& Neglect. 2018; 84: 106-114. PMid: 30077049. https ://doi.org/10.101 6/j.chiabu.2018.07.004

[4] Lind K, Toure H, Brugel D, et al. Extended follow-up of neurological, cognitive, behavioral and academic outcomes after severe abusive head trauma. Child Abuse \& Neglect. 2016; 51: 358-367. PMid: 26299396. https ://doi .org/10.1016/j . chiabu. 2015. 08.001

[5] Iqbal O’Meara AM, Sequeira J, Miller Ferguson N. Advances and Future Directions of Diagnosis and Management of Pediatric Abusive Head Trauma: A Review of the Literature. Frontiers in Neurology. 2020; 11: 118. PMid: 32153494. https://doi.org/10.3389/fn eur. 2020.00118

[6] Johnson JD, Cocker K, Chang E. Infantile colic: recognition and treatment. American Family Physician. 2015; 92(7): 577-582.

[7] Squier W. The Shaken Baby syndrome: pathology and mechanisms. Acta Neuropathol. 2011; 122: 519-42. PMid: 21947257. https://doi.org/10.1007/s00401-011-0875-2

[8] Gordy C, Kuns B. Paediatric Abusive Head Trauma. Nursing Clinics of North America. 2013; 48: 193-201. PMid: 23659807. https: //doi.org/10.1016/j.cnur.2013.01.013

[9] Child Welfare Information Gateway (CWIG). Preventing Child Maltreatment and Promoting Well-being: A network for Action Resource Guide. 2013. Available from: http://www.childwelfare.gov/p reventing/preventionmonth/guide2013/

[10] Barr RG. Who is behind the period of purple crying program? The National Center for Shaken Baby Syndrome. 2014. Available from: www.PurpleCrying.info/sub-pages/articles-andau thors.php

[11] Smarius IJCA, Strieder TGA, Loomans EM, et al. Excessive infant crying doubles the risk of mood and behavioural problems at age 5: evidence for mediation by maternal characteristics. European Child \& Adolescent Psychiatry. 2016; 15: 1-10. PMid: 27422707. https://doi.org/10.1007/s00787-016-0888-4

[12] Tursz A, Cook J. Epidemiological data on shaken baby syndrome in France using Judicial Sources. Pediatric Radiology. 2014; 44(4). PMid: 25501736. https://doi.org/10.1007/s00247-014-3 097-7

[13] Cook F, Bayer J, Le H, et al. Baby Business: A randomized controlled trial of a universal parenting program that aims to pre- vent early infant sleep and cry problems and associated parental depression. BMC Paediatrics. 2012; 12: 13. PMid: 22309617. https://doi.org/10.1186/1471-2431-12-13

[14] Halpern R, Coelho R. Excessive crying in infants. Journal de Paediatrics. 2016; 92(3): S40-S45. https ://doi.org/10.1016/j.jp edp. 2016.03 .014

[15] Petzoldt J, Wittchen H, Einsle F, et al. Maternal anxiety versus depressive disorders: specific relations to infants crying, feeding and sleeping problems. Child, Care, Health and Development. 2016; 42(2): 231-245. PMid: 26490836. https://doi.org/10.1111/ cch. 12292

[16] Rideout L. Nurses' Perceptions of Barriers and Facilitators Affecting the Shaken Baby Syndrome Education Initiative: An Exploratory Study of a Massachusetts Public Policy. Journal of Trauma Nursing. 2016; 23(3): 125-137. PMid: 27163220. https ://doi.org/10.1 $097 /$ JTN .0000000000000206

[17] Fraser JA, Flemington T, Doan T, et al. Prevention and recognition of abusive head trauma: training for healthcare professionals in Vietnam. Acta paediatrica. 2017; 106(10): 1608-1616. PMid: 28685899. https://doi.org/10.1111/apa.13977

[18] Johnson JD, Cocker K, Chang E. Infantile Colic: Recognition and treatment. American Family Physician. 2015; 92(7): 577-582.

[19] Nocera M, Shanahan M, Murphy RA, et al. A state wide nurse training program for a hospital based infant abusive head trauma prevention program. Nurse Education in Practice. 2016; 16(1): e1-e6. PMid: 26341727. https://doi.org/10.1016/j.nepr.2015.07.013

[20] Ashton R. Practitioner Review: beyond shaken baby syndrome: what influences the outcomes for infants following traumatic brain injury. J Child Psychol Psychiatry. 2010; 51(9): 967-980. PMid: 20524940. https : //doi.org/10.1111/j.1469-7610.2010.02272.x

[21] Agency for health care research and quality (AHRQ). Educational materials enhance the ability of new parents to understand and cope with infants crying. AHRQ health care Innovations Exchange. 2013

[22] Fallon C, Monique S, Rebecca G, et al. Comparison of Methods for Recruiting and Engaging Parents in on line Interventions: Study protocol for the cry baby infant sleep and settling program. BMC Paediatrics. 2015; 15: 174. PMid: 26556032. https://doi.org/ 10.1186/s12887-015-0502-9

[23] Simonnet H, Laurent-Vannier A, Yuan W, et al. Parents' behavior in response to infant crying: abusive head trauma education. Child Abuse \& Neglect. 2014; 38(12): 1914-1922. PMid: 25043922 https://doi.org/10.1016/j.chiabu.2014.06.002

[24] Taşar MA, Bilge YD, Şahin F, et al. Shaken baby syndrome prevention programme: A pilot study in Turkey. Child Abuse Review. 2015; 24(2): 120-128. https ://doi .org/10.1002/car. 2326

[25] Trossman S. PRACTICE Preventing tragedies New Mexico nurses lead initiative on shaken baby syndrome. The American Nurse. 2016; 48(4): 13.

[26] Peterson C, Xu L, Florence C, et al. Annual cost of US hospital visits for pediatric abusive head trauma. Child Maltreatment. 2015; 20(3): 
162-169. PMid: 25911437. https ://doi.org/10.1177/107755 9515583549

[27] Ludvigsson JF. Extensive shaken baby syndrome review provides a clear signal that more research is needed. Acta Paediatrica. 2017; 106(7): 1028-1030. PMid: 28370396. https ://doi.org/10.111 1/apa. 13765

[28] Tasar A, Sarten T. International collaboration on prevention of shaken baby syndrome - an ongoing project/intervention. Pediatric and International Child Health. 2017; 33(4): 233-237. PMid: 24070038 https://doi.org/10.1179/2046905513Y.0000000093

[29] Suleiman M. Parental Knowledge of Shaken Baby Syndrome: Effects of a High Risk Parent Teaching Program on Incidence of Abusive Head Trauma. Undergraduate Research. 2015; 8. http://digita lcommons. lasalle.edu/undergraduateresearch/8

[30] Zeifman DM, St James-Roberts I. Parenting the crying infant. Curr Opin Psychol. 2017; 15: 149-154. PMid: 28685155. https://doi . org/10.1016/j.copsyc. 2017.02.009

[31] Fujiwara T. Effectiveness of Public Health Practices against Shaken Baby Syndrome/Abusive Head Trauma in Japan. Public Health. 2015; 129(5): 475-82. PMid: 25744111. https ://doi .org/10.1016/j. puhe. 2015.01.018

[32] Ornstein AE, Fitzpatrick E, Hatchette J, et al. The impact of an educational intervention on knowledge about infant crying and abu- sive head trauma. Paediatr Child Health. 2016; 21(2): 74-78. PMid: 27095881. https://doi.org/10.1093/pch/21.2.74

[33] Wiley M, Schultheis A, Francis B, et al. Parents' Perceptions of Infant Crying: A Possible Path to Preventing Abusive Head Trauma. Acad. Pediatr. May-Jun 2020; 20(4): 448-454. PMid: 31629119. https://doi.org/10.1016/j.acap.2019.10.009

[34] Fujiwara T, Yamada F, Okuyama M, et al. Effectiveness of educational materials designed to change knowledge and behaviour about crying and shaken baby syndrome: A replication of a randomized controlled trial in Japan. Child Abuse \& Neglect. 2012; 36(9): 613 620. PMid: 22954642. https://doi.org/10.1016/j.chiabu. 2 012.07 .003

[35] Mohebatia LM, Caulfield LE, Martinezc H. How much does your baby cry? Expectations, patterns and perceptions of infant crying in Mexico. Bol Med Hosp Infant Mex. 2014; 71(4): 202-210. PMid: 29421252. https://doi.org/10.1016/j.bmhimx. 2014. 08.002

[36] Lopez-Bushnell K, Torrez D, Robertson J, et al. Shaken Baby Syndrome: A hospital-based education and prevention program in the intermediate care and the newborn intensive care nurseries. Journal of Neonatal Nursing. 2017(23): 142-150. https : //doi .org/10.1 $016 / j \cdot j n n .2016 .09 .004$ 